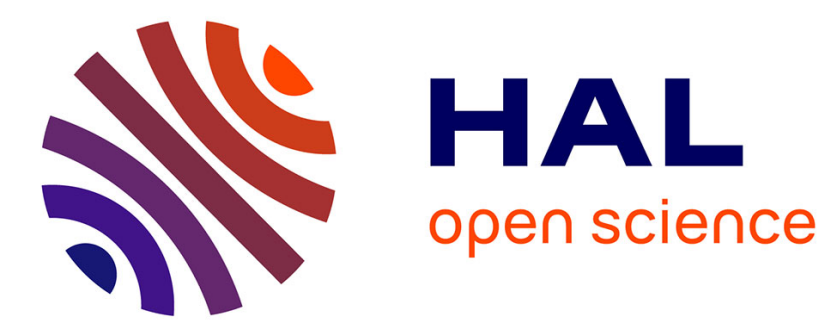

\title{
Dynamic recrystallization of spheroidal graphite iron during hot cutting operations.
}

Kevin Le Mercier, Michel Watremez, Laurence Fouilland-Paille, Laurent Dubar

\section{- To cite this version:}

Kevin Le Mercier, Michel Watremez, Laurence Fouilland-Paille, Laurent Dubar. Dynamic recrystallization of spheroidal graphite iron during hot cutting operations.. ESAFORM 2015, 2015, Graz, Austria. pp.1235-1240, 10.4028/www.scientific.net/KEM.651-653.1235 . hal-01178172

\section{HAL Id: hal-01178172 \\ https://hal.science/hal-01178172}

Submitted on 27 Aug 2015

HAL is a multi-disciplinary open access archive for the deposit and dissemination of scientific research documents, whether they are published or not. The documents may come from teaching and research institutions in France or abroad, or from public or private research centers.
L'archive ouverte pluridisciplinaire HAL, est destinée au dépôt et à la diffusion de documents scientifiques de niveau recherche, publiés ou non, émanant des établissements d'enseignement et de recherche français ou étrangers, des laboratoires publics ou privés. 


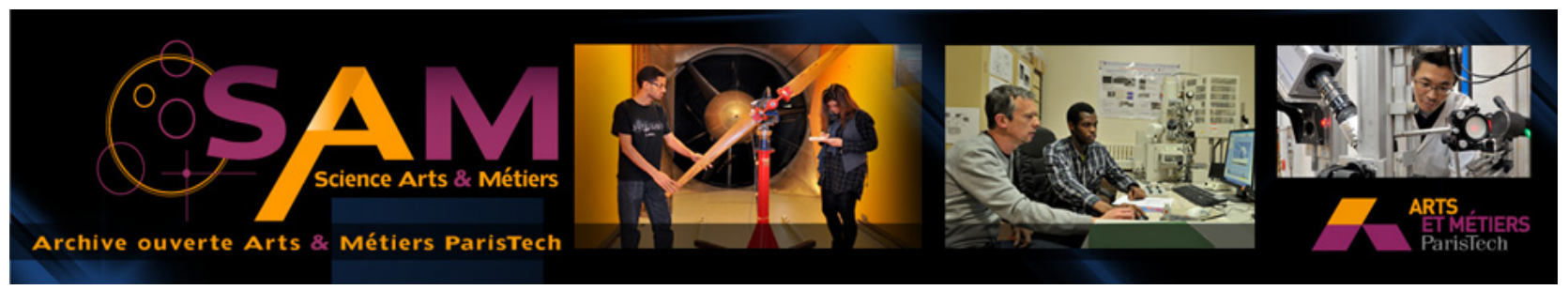

\section{Science Arts \& Métiers (SAM)}

is an open access repository that collects the work of Arts et Métiers ParisTech researchers and makes it freely available over the web where possible.

This is an author-deposited version published in: http://sam.ensam.eu

Handle ID: .http://hdl.handle.net/10985/9822

\section{To cite this version :}

Laurence FOUILLAND, Kévin LE MERCIER, Michel WATREMEZ, Laurent DUBAR - Dynamic recrystallization of spheroidal graphite iron during hot cutting operations. - In: ESAFORM 2015, Autriche, 2015 - Key Engineering Materials (ESAFORM 2015) - 2015 


\title{
Dynamic recrystallization of spheroidal graphite iron during hot cutting operations
}

\author{
K. Le Mercier ${ }^{1,2, a,{ }^{*}}$, M. Watremez ${ }^{1,2, b}$, L. Fouilland-Paille ${ }^{3, c}$, and L. Dubar ${ }^{1,2, d}$ \\ ${ }^{1}$ Univ Lille Nord de France, F-59000 Lille, France \\ ${ }^{2}$ UVHC, LAMIH UMR CNRS 8201, F-59313 Valenciennes, France \\ ${ }^{3}$ Arts et Métiers ParisTech, MSMP EA4106, F-51006 Châlons en Champagne, France \\ akevin.lemercier@univ-valenciennes.fr, ${ }^{b}$ michel.watremez@univ-valenciennes.fr, \\ 'laurence.fouilland-paille@ensam.eu, ${ }^{d}$ laurent.dubar@univ-valenciennes.fr
}

Keywords: SG iron, Hot Cutting, Dynamic Recrystallization, Finite Element Modelling.

\begin{abstract}
The objective of the present paper is to analyse the dynamic recrystallization process occurring during the hot cutting of spheroidal graphite iron. In the first instance, hot cutting tests are performed with an orthogonal cutting test bench. The emergence of dynamic recrystallization is highlighted thanks to microstructural observations. Then, a finite element model of the hot cutting operation is introduced. The material behaviour is modelled with a specific constitutive model considering the influence of dynamic recrystallization on the plastic flow stress. Finally, the predictive response of this model is compared to the experimental observations.
\end{abstract}

\section{Introduction}

Heat treated spheroidal graphite (SG) iron also called austempered ductile iron (ADI) has emerged in several fields such as automotive or railway industries. Through a specific heat treatment called austempering, ADI provide an efficient compromise between strength, fracture toughness and high resistance to abrasive wear at low cost. Therefore, these specific materials could replace forged steels for many manufactured components thanks to an attractive combination between their mechanical characteristics and their densities [1].

However, during the part manufacturing, a combined casting and forging process followed by the austempering treatment is necessary to increase competitiveness. Risers and feeder head are then removed at $1000^{\circ} \mathrm{C}$ just after the casting operation to save time and energy but this cutting operation may cause surface degradations compromising the process viability [2].

Specific experiments on an orthogonal cutting test bench reproducing the hot cutting process parameters are first carried out with EN-GJS-700 iron. These tests highlight that the emergence of surface defects is related to the dynamic recrystallization activation. This is enhanced by the observation of post-mortem metallography.

In order to get the local conditions of the hot cutting operation (temperatures, strain rate and plastic strain), a finite element model is developed with the Abaqus/Explicit software. A typical metallurgical based model is introduced in modelling via a user subroutine. This constitutive law developed by Kim et al. reproduces the effects of dynamic recrystallization on the material behaviour and allows the evolution of this phenomenon to be monitored.

\section{Experimental study of the hot cutting operation}

Testing device. The experiments are conducted on an orthogonal cutting test bench with ENGJS-700 iron specimens (Fig.1). These specimens were machined to replicate the feeder head obtained after casting. Firstly, specimens are austenitized at $1000^{\circ} \mathrm{C}$. Then, the high strength steel (HSS) cutting tool moves against the feeder head replication while the specimen's base is maintained in a refractory insert bed. This prevents from heat losses during the test. Thereafter, the specimen is oil quenched to freeze its microstructure. Two different cutting speeds $\left(1.3-1.6 \mathrm{~m} . \mathrm{s}^{-1}\right)$ and a single rake angle of the tool $\left(-10^{\circ}\right)$ are tested. 
The test is recorded with a high speed camera. The tool is covered by a speckle pattern to get its velocity during the cutting operation through digital image correlation. The cutting loads are monitored in the 3 directions.

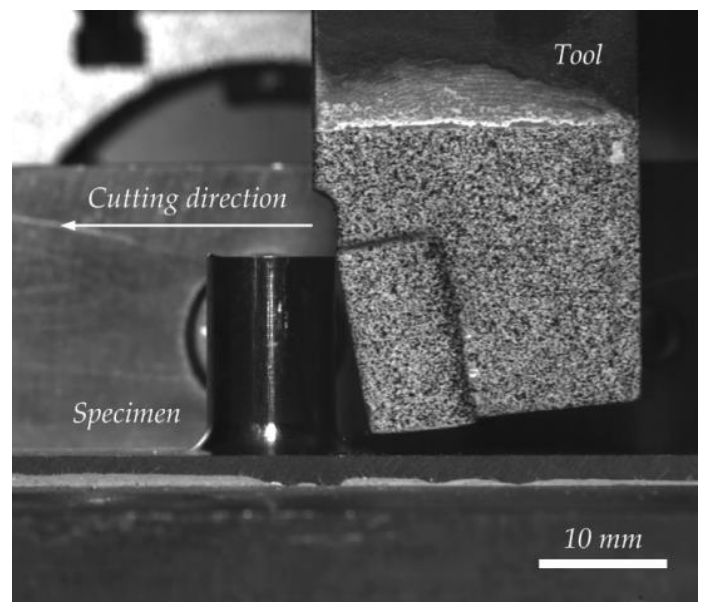

Figure 1 - Clamped specimen and cutting tool.

Experimental results. The cutting forces obtained for both test conditions are displayed as function of the tool displacement (Fig.2). At $1.3 \mathrm{~m} . \mathrm{s}^{-1}$, a steady state is observed before the crack initiation which conforms to a ductile behaviour. As the fracture occurs earlier for the highest cutting speed, the experimental force does not reach a steady state. The failure is thus expected to be brittle.

In order to confirm these assumptions, microstructural analyses are performed in a cross section under the cut surfaces. Two kinds of fracture are observed in the primary shear zone. For the lowest cutting speed, a ductile fracture allows a cutting operation without surface degradation whereas for the highest cutting speed, a brittle fracture appears.

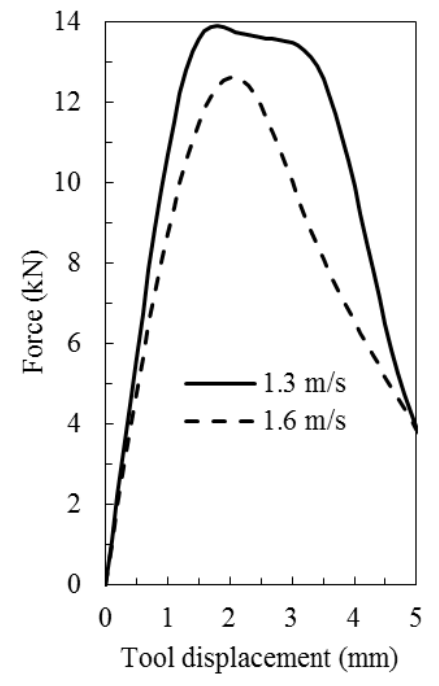

a- Experimental cutting forces
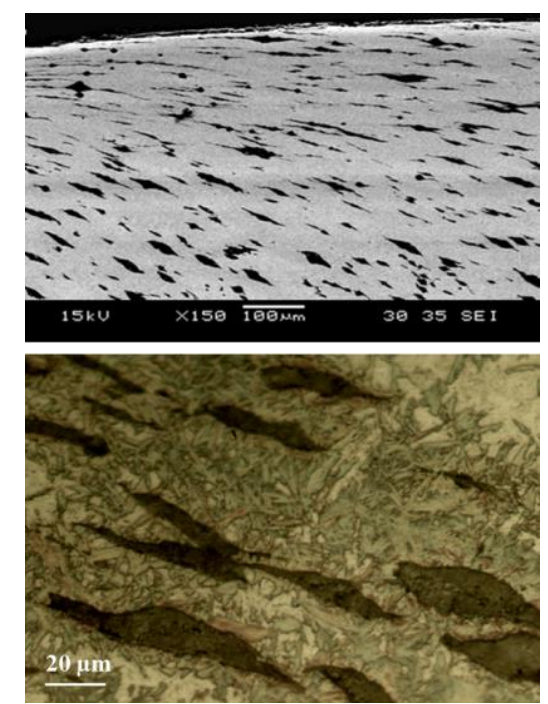

b- Ductile fracture $\left(1.3 \mathrm{~m} \cdot \mathrm{s}^{-1}\right)$
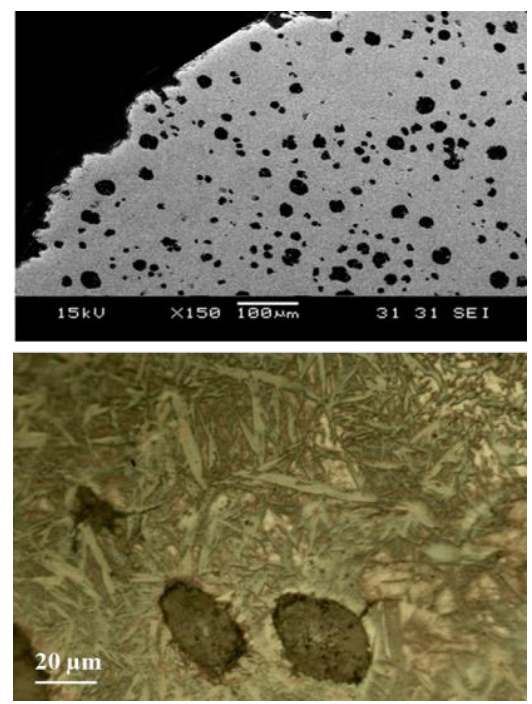

c- Brittle fracture $\left(1.6 \mathrm{~m} \cdot \mathrm{s}^{-1}\right)$

Figure 2: Cutting forces and microstructural details in a cross-section of both tested specimens.

Microstructural details in a cross section (Fig.2) show a grain refinement when a ductile fracture occurs. This highlights the occurrence of dynamic recrystallization within the shear zone during the cutting operation.

For higher cutting speed, the size of martensite needles is more significant which suggests that dynamic recrystallization has not been activated. The brittle-ductile transition is linked with the activation of this phenomenon [2]. 


\section{Numerical modelling of the hot cutting operation}

Finite element model. The finite element model of the hot cutting operation is carried out with the Abaqus/Explicit software. Fig.3 shows the initial mesh applied to the half of the workpiece. The chosen elements are 8-nodes 3D solid elements (C3D8RT). A symmetry condition on z-axis is applied to the front face of the workpiece. The other faces except the cylinder and the top faces have all of their degrees of freedom constrained. The tool is modelled by a rigid surface and moves in the cutting direction with a constant velocity.

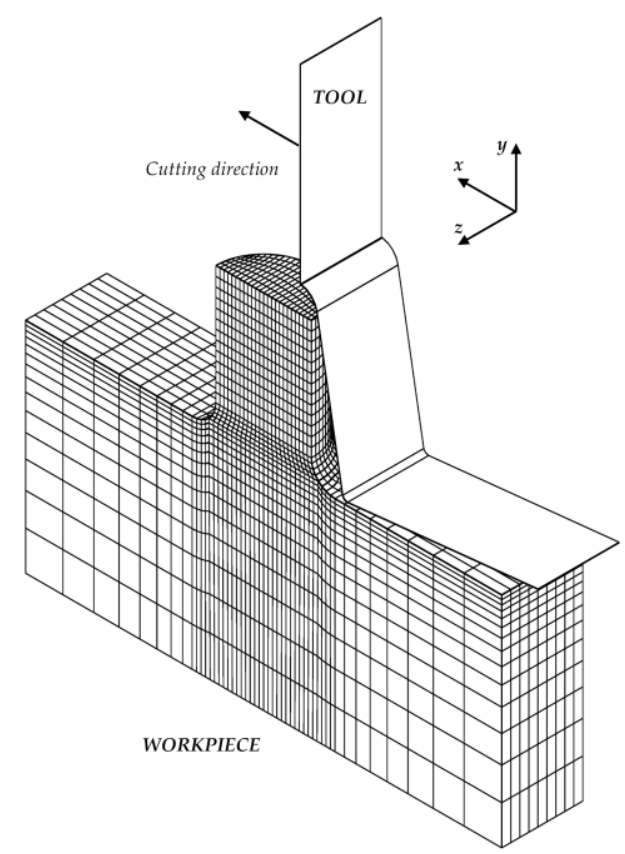

Figure 3: Initial mesh configuration of the finite element model.

A Coulomb's friction law with a constant coefficient $\mu$ set to 0.1 is used to model the contact between the tool and the workpiece. The initial temperature of the test is applied to the specimen which is assumed to be adiabatic. The workpiece material is modelled as elasto-plastic with isotropic hardening. The flow stress is defined by Kim et al. model. No fracture criterion is introduced in this simulation as the focus is made on the beginning of the hot cutting operation.

Kim et al. model [3]. This metallurgical based model is explained in Fig.4. According to Medina et al. [4], a softening is observed when dynamic recrystallization appears because of the induced microstructural changes. In this model, the yield stress $\sigma_{y}$ is expressed by $\sigma_{(W H+D R)}$ representing work hardening and dynamic recovery lowered by $\sigma_{D R X}$ representing dynamic recrystallization. $\sigma_{0}, \sigma_{s}$ and $\sigma_{p}$ are respectively the initial yield stress, the steady state stress and the peak stress. $m$ is the work hardening exponent and $C$ is a coefficient depending on deformation.

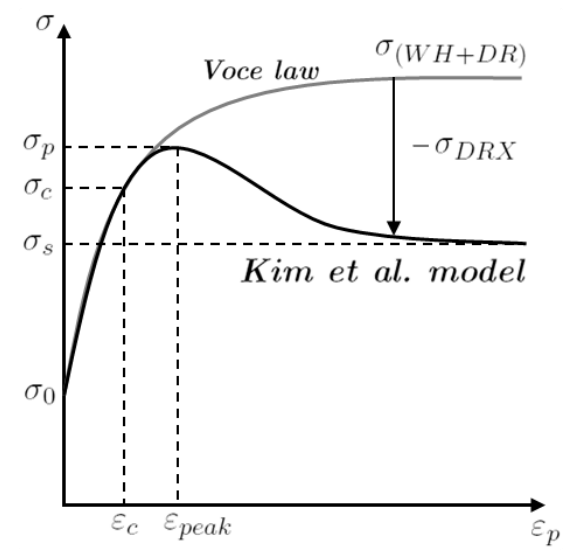

$$
\left\{\begin{array}{l}
\sigma_{y}=\sigma_{(W H+D R)}-\sigma_{D R X} \\
\sigma_{(W H+D R)}=\sigma_{0}+\left(\sigma_{p}-\sigma_{0}\right)\left[1-\exp \left(-C \varepsilon_{p}\right)\right]^{m} \\
\varepsilon_{p}<\varepsilon_{\text {peak }}, \sigma_{D R X}=0 \\
\varepsilon_{p} \geq \varepsilon_{\text {peak }}, \sigma_{D R X}=\left(\sigma_{p}-\sigma_{s}\right)\left[\frac{X_{D R X}\left(\varepsilon_{p}\right)-X_{\varepsilon_{p e a k}}}{1-X_{\varepsilon_{\text {peak }}}}\right] \\
X_{D R X}\left(\varepsilon_{p}\right)=1-\exp \left[-\left(\frac{\varepsilon_{p}-\varepsilon_{c}}{\varepsilon^{*}}\right)^{m^{\prime}}\right] \\
\sigma_{0}, \sigma_{s}, \sigma_{p}, C, m, m^{\prime}, \varepsilon_{c}, \varepsilon^{*}=f(Z) \text { with } f(Z)=K_{i} Z^{m_{i}}
\end{array}\right.
$$

Figure 4: Kim et al.'s model. [6] 
The beginning of dynamic recrystallization depends on the critical strain $\varepsilon_{c}$ and the maximum softening rate is represented by the strain $\varepsilon^{*}$ [5]. These two last parameters have directly an effect on the $\sigma_{D R X}$ term which involves the volume fraction of dynamically recrystallized grains $X_{D R X}$ arising from an Avrami equation. $m^{\prime}$ is the Avrami's constant. $X_{\varepsilon_{\text {peak }}}$ is the volume fraction of dynamic recrystallization at peak strain.

Each parameter of this model is described by the strain rate sensitivity $m_{i}$ and the normalization constant $K_{i}$. They also depend on the Zener-Hollomon parameter [6] expressed in Eq.1 coupling temperature $\mathrm{T}$ and strain rate $\dot{\varepsilon}$. Briottet et al. [7] have introduced Eq.2 using also the Boltzman constant $\mathrm{R}$, to determine the activation energy $\mathrm{Q}$.

$Z=\dot{\varepsilon} \exp \left(\frac{Q}{R T}\right)$

$Q=\frac{R}{m}\left|\frac{\partial \ln \left(\sigma_{0}\right)}{\partial(1 / T)}\right|_{\bar{\varepsilon}, \dot{\bar{\varepsilon}}} ; \quad m=\left|\frac{\partial \ln \left(\sigma_{0}\right)}{\partial \ln (\dot{\bar{\varepsilon}})}\right|_{\bar{\varepsilon}, T}$

This model has already been identified through uniaxial compression tests in a previous study [8]. As shown in Fig.5, the accuracy of model is acceptable for a large range of temperatures.
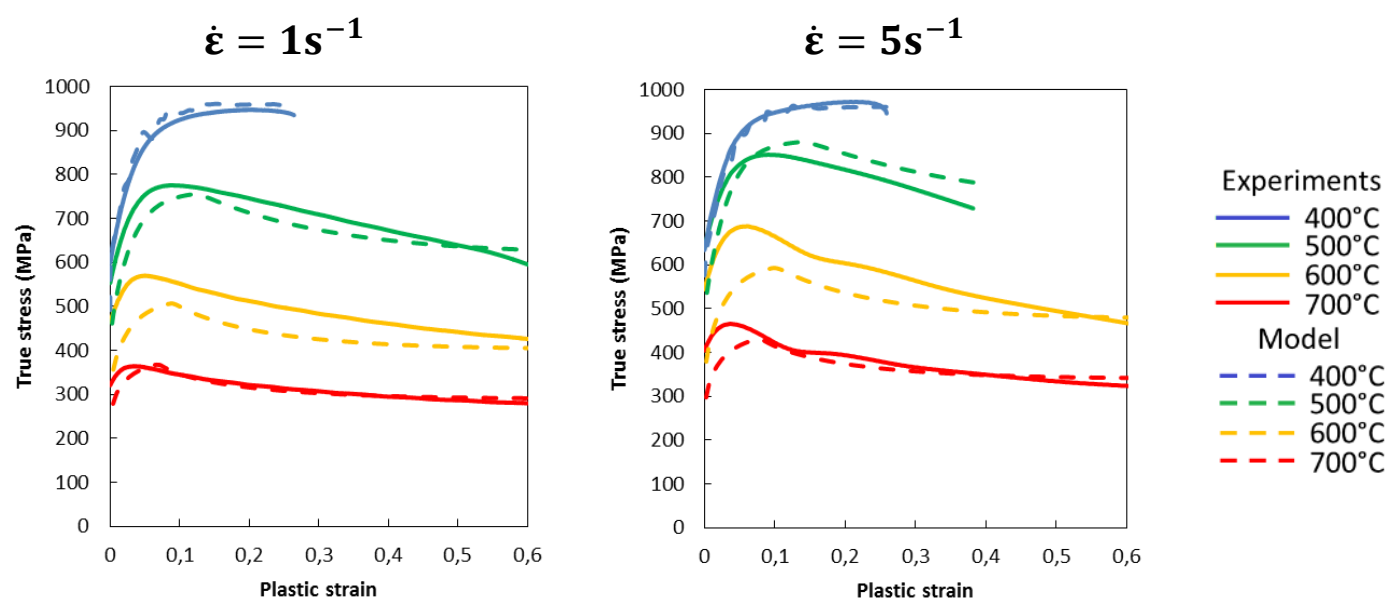

Figure 5: Comparison between the numerical prediction of Kim et al. model and uniaxial compression stress-strain curves [8].

Numerical results. The comparison between numerical and experimental cutting forces before the crack initiation is performed in Fig.6.

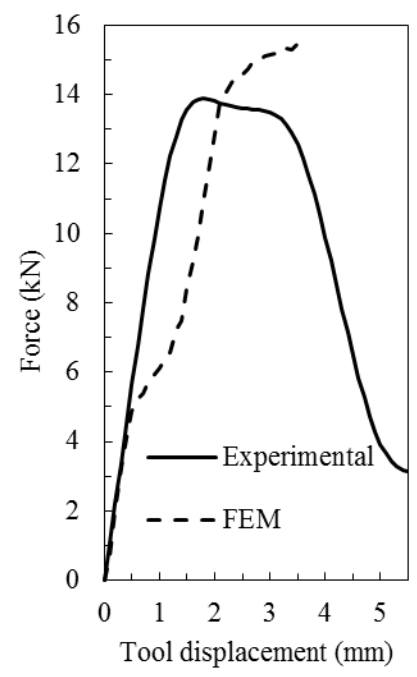

Figure 6: Comparison between experimental and numerical results $\left(1.3 \mathrm{~m} . \mathrm{s}^{-1}\right)$. 
The predicted resulting forces are close between both test configurations (Tab.1). Unfortunately, the prediction for the high cutting speed is not efficient. This can be explained by the nonimplementation of a fracture criterion in the modelling. Indeed, instead of plummeting after the crack initiation, the numerical force keeps increasing.

Table 1: Comparison between experimental and numerical peak forces.

\begin{tabular}{rrr}
\hline Cutting speed $\left(\mathrm{m} . \mathrm{s}^{-1}\right)$ & Experimental force $(\mathrm{kN})$ & Numerical prediction $(\mathrm{kN})$ \\
\hline 1.3 & 13.9 & 15.4 \\
1.6 & 12.6 & 15.7 \\
\hline
\end{tabular}

Thanks to Kim et al. model, the evolution of dynamic recrystallization within the specimen has been monitored. Fig.7 shows the volume fraction of dynamically recrystallized grains $X_{D R X}$ for the test performed at $1.3 \mathrm{~m} . \mathrm{s}^{-1}$. The finite element model predicts the occurrence of dynamic recrystallization within the shear zone.

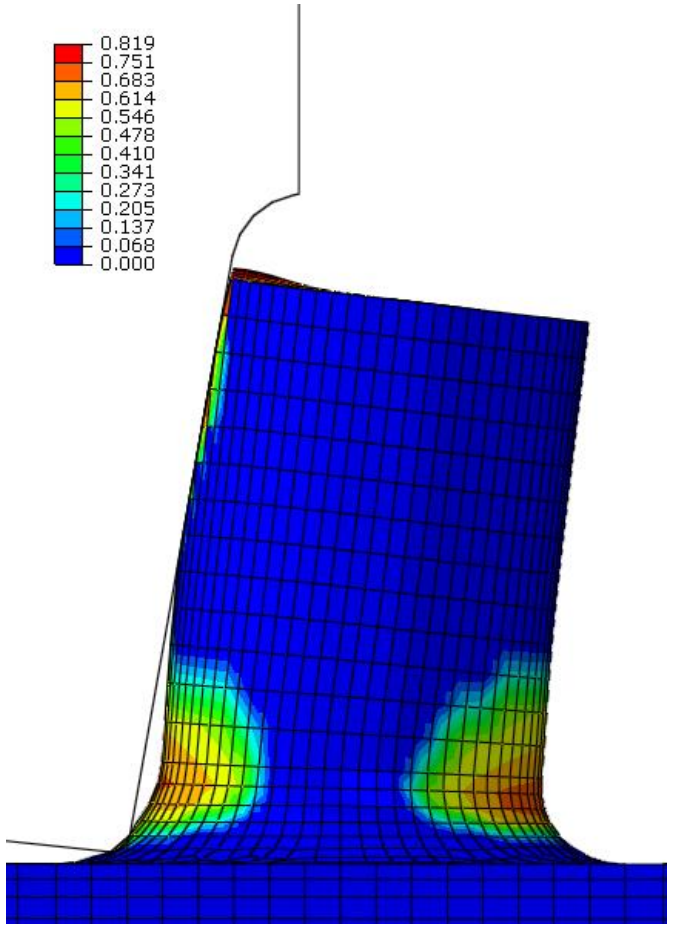

a- Volume fraction of dynamically recrystallized grain within the specimen $\left(1.3 m \cdot s^{-1}\right)$.

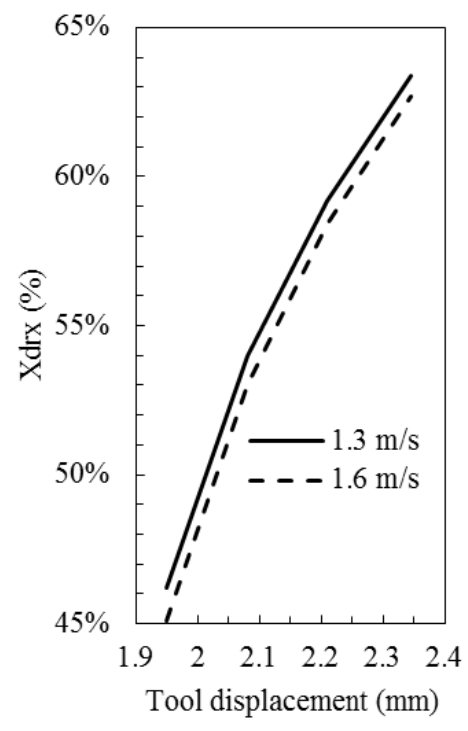

$b$ - Comparison of $X_{D R X}$ maxima for both test conditions in the shear zone.

Figure 7: Study of the volume fraction of dynamically recrystallized grains within the specimens.

For both tested conditions, dynamic recrystallization is predicted. However, for the low cutting speed, the dynamic recrystallization process is more pronounced, $X_{D R X}$ is higher for a same tool position. Furthermore, this slight gap is observed for a tool position corresponding to the crack initiation $(2 \mathrm{~mm})$. The delay observed on $X_{D R X}$ at $1.6 \mathrm{~m} \cdot \mathrm{s}^{-1}$ is also a delay in the softening mechanism leading to the brittle failure.

\section{Conclusion}

A typical cutting process and its finite element model have been introduced in this paper. Thanks to the implementation of a specific constitutive model, the numerical predictions highlighted some explanations concerning the activation of dynamic recrystallization within the shear zone.

Furthermore, this finite element simulation revealed that the softening mechanism allows a ductile shear regime to take effect instead of a brittle failure only if the volume fraction of dynamically 
recrystallized grain reaches a specific level. In order to understand the competition between failure and dynamic recrystallization process, further works are needed to identify a fracture criterion for the spheroidal graphite.

\section{References}

[1] B.V. Kovacs, Development of austempered ductile iron (ADI) for automobile crankshafts. Journal of Heat Treating, vol.5, pp. 55-60, 1987.

[2] L. Fouilland-Paillé, M. El Mansori, Experimental study of the brittle ductile transition in hot cutting of SG iron specimens. Journal of Materials Processing Technology, vol. 213, pp. 201213, 2013.

[3] S.I. Kim, Y. Lee, S.M. Byon, Study of constitutive relation of AISI 4140 steel subject to large strain at elevated temperatures. Journal of Materials Processing Technology, vol.140, pp. 8489, 2003.

[4] S.F. Medina, C.A. Hernandez, Modelling of the dynamic recrystallization of austenite in low alloy and microalloyed steels. Acta Metallurgica, vol.1, pp. 165-171, 1996.

[5] O. Lurdos, F. Montheillet, G. Damamme, Empirical and physically based flow rules relevant to high speed processing of 304L steel. International Journal of Material Forming, vol.1, pp. 1431-1434, 2008.

[6] C. Zener, J.H. Hollomon, Effect of strain rate upon plastic flow of steel. Journal of Applied Physics, vol.15, pp. 22-32, 1944.

[7] L. Briottet, J.J. Jonas, F. Montheillet, A mechanical interpretation of the activation energy of high temperature deformation in two phase materials, Acta Materialia, vol.44, pp. 1665-1672, 1996.

[8] K. Le Mercier, M. Watremez, L. Fouilland, J.D. Guérin, L. Dubar, Thermo-mechanical behaviour of spheroidal graphite iron, Key Engineering Materials (ESAFORM 2014), pp. 1250-1257, 2014. 